\title{
A Conceptual Benefits Realization Model for Minimization of Transaction Costs in Building Energy Efficiency (BEE) Affordable Housing Delivery
}

\author{
Abdulazeez U. Raji* \\ ${ }^{1}$ Department of Estate Management, Bayero University, Kano. PMB 3011 Kano State, Nigeria
}

\begin{abstract}
Energy efficiency is fundamental to enhancing homes affordability. There are several unique challenges to affordable housing that owner-developers need to address in order for energy efficiency to make significant economic sense. Issues such as Transaction Costs (TCs) plays a significant role in achieving building energy efficiency (BEE) for affordable housing delivery. It is evident that split incentives, information asymmetry, institutional transition, opportunistic behavior, and ill-informed users incur different levels of TCs and affect stakeholder's willingness to take part in BEE for affordable housing. A better understanding of the nature and structure of TCs is indispensable to enhance the market-drive and investment for BEE affordable housing. Uncertainty, specific investment, frequency, and bounded rationality seen as the key dimensions of TCs. The research focuses on how to minimize TCs involve in BEE affordable housing delivery. It was found in the literature that, the level of TCs for building energy efficiency estimated at $20.5 \%$ of total project costs. A conceptual competency-driven benefits realization model is proposed for minimizing TCs taking into consideration the peculiarities of the current housing projects delivery. This research aims to establish the significance of leveraging on BEE project teamcompetency and commitment organized within a strategic Benefits Realization Management framework to optimize client's benefits regarding minimizing TCs. The focus is on the aspect of a developer's competencies and their project team commitment concerning minimizing TCs that structured within a Benefits Realization Management (BRM) practice. This model is proposed as a pro-active enabler tool to achieve Value for Money in BEE affordable housing projects. This paper is part of a series of publications.
\end{abstract}

\section{Introduction}

Construction industry could contribute significantly to the sustainability of future development. Buildings account for $40 \%$ of global energy consumption and nearly one-third of global $\mathrm{CO}_{2}$ emissions [1]. New houses that are not energy efficient are continually built every day, and the existing inefficient housing stocks will remain standing in the next 50 years [2]. In Nigeria, the energy usage of buildings is proliferating due to rural-urban migration and as more people move into modern homes and acquire amenities and appliances such as heating, cooling, and refrigeration. Energy demand in the Nigerian housing sector is expected to proliferate in parallel with economic and population growth. Attractive opportunities exist to reduce housing energy demand and use at lower costs and higher returns than in other sectors. When compared to developing countries in general, they lack the incentive and technical know-how to pursue the goal of greater sustainability agenda [3]. There is the need for the developing countries to advance their level of awareness and contribute immensely to the Building Energy Efficiency (BEE) development battle to redefine the fight against climate change and address the global environmental concerns [4]. It is evident that up to $50 \%$ of total energy is utilized by buildings, which include the materials development, construction and building lifecycle operation [5]. In Nigeria, the case is similar, as buildings consume about $75 \%$ of electricity, primarily for air-conditioning due to the tropic climate characterized by sunny and hot weather. This seen as the fundamental point and source of Nigeria's greenhouse gas emissions.

There are various research corroborating to the collective benefits of propagating green building. Though, when compared to the conventional building's approach, green buildings projects are often seen to have a higher initial cost at both the design and construction stages. Certainly, uncertainties exist in the process and route of delivering green buildings, which involves an extraordinary contingency sum to apportion in the project budget. Without clearly define costs and benefits, the perceived higher initial costs and TCs along with their attendant extra risks, further discourage prospective developers and stakeholders from embarking on green building projects. The clients' project managers play a vital role in integrating sustainability to deliver a

\footnotetext{
* Corresponding author: auraji.esm@buk.edu.ng
} 
sustainable facility or building at both the design and construction stages while keeping in mind the project target of cost and time requirements of the client or project [6-8]

It also evident that only the developers with financial capability can survive and leverage on the benefits realization actively in the sector. The key players have little or no incentive to risk into green building business. The barrier to the building energy efficient market entry is higher when compared with conventional building approach; this is due to new information search, expertise, lack of technical knowhow of new technology, and financial risk involved. However, if there is an establish asymmetric information with regards to the standards quality or essential requirements that unenforced on the market, the developers' opportunistic behavior might take center stage and they may continue to produce conventional buildings [9].

The actions of minimizing TCs is seen as being oriented towards benefits realization. The attempt here is to provide a basis to realize benefits for the client by focusing on key existing developers' capabilities, viewed as corporate social responsibility within the construction industry, focusing on the soft human factors component. Taking BEE affordable housing delivery scheme as being best suited to test this principle of targeting benefits maximization for the client, an analysis of developer's team-commitment and team-competence is undertaken to evaluate their significance in minimizing Transaction Costs (TCs). TCs have variously described as being a social waste of wealth [10-11].

\subsection{Research theoretical framework}

Affordable housing developers' team-commitment and team-competency are two critical aspects of developer organizational capability that significantly influence on organizational performance. The affordable housing developer commitment and competency measures will be developed using the Delphi technique. These focused measures were being collated from extant literature under the broad category of organizational commitment and competency and articulated as a theoretical framework (refer to Figure 1). Further detailed discussion on the Delphi technique will be provided in the subsequent publication. The responses of the experts through the rounds of Delphi will facilitate the final consensus view of the BEE affordable housing experts which will constitute the final research questionnaire measurement constructs.

The epistemological basis for this work is embedded within the Lean Production Theory [10], wherein knowledge or action in production is to premised on principles related to minimizing waste and maximizing value [12]. In this paper BEE, affordable housing performance addresses regarding minimizing TCs in order to maximize benefits for BEE affordable housing clients in the construction industry.

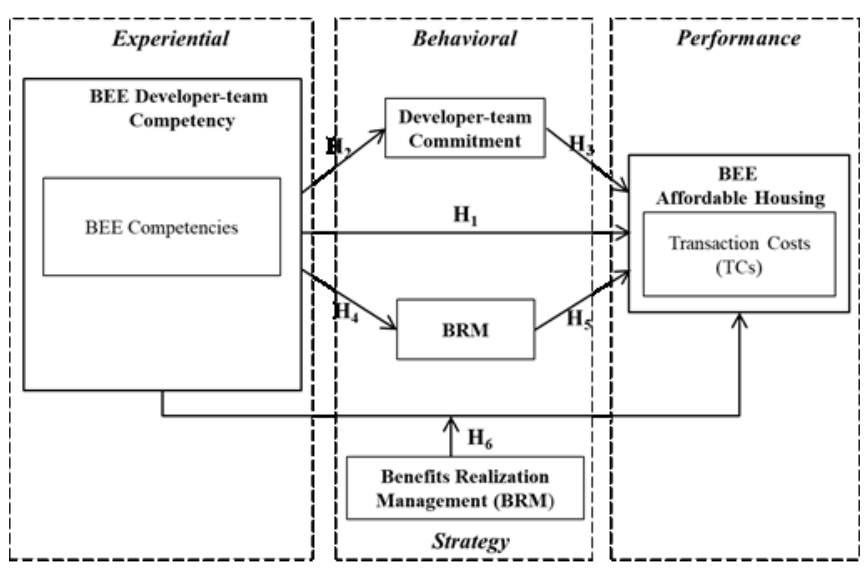

Fig. 1. Theoretical framework

The ultimate deduction is that BEE affordable housing clients rely on the attitude and behavior of the developer team to act in the client's best interest. Hence, in the absence of such behavior or commitment from the developers' team, the BEE affordable housing clients' benefits would be afflicted by uncertainties, consequently lowering the performance level and increasing TCs. The conceptualization of the theoretical framework (refer to Figure 1) based on Boyatzis's [13] Theory of Action and Job Performance. According to Boyatzis [13] (2008) theory of performance is the basis for the concept of competency. As maximum performance is believed to occur when individual capability or talent is consistent with the needs of the job demands and the organizational environment. The framework was further developed using Williamson's [14] analysis of the key contributors of TCs, namely: the economic actors' behavioural assumptions, the lack of competency resulting in bounded rationality [15]; and transaction characteristics such as split incentive, information asymmetry, opportunistic behaviour, illinformed users and institutional transition [16] of the BEE affordable housing projects. Hence, it hypothesized that BEE affordable housing TCs could be minimized by emphasising on the different dimensions of developers' team-competency and team-commitment as shown in Figure 1. The main hypothesis of the framework are:

\subsubsection{The main hypothesis}

$H^{\mathrm{A}}$ : BEE affordable housing developers' TeamCompetency positively influences TCS

$H^{\mathrm{B}}$ : BEE affordable housing developers' TeamCommitment positively influences TCs

$H^{\mathrm{C}}$ : BEE affordable housing developers' Benefits Realization Strategy positively influences TCs 


\section{Building energy efficiency affordable housing}

The planet earth is running out of finite resources of fossil fuels, and at the same time, global warming is threatening to change the climate into a destructive force that could change the world [17]. Meanwhile, buildings are responsible for over $50 \%$ of total energy consumption in Nigeria, part of the solution must involve ensuring the building to be more efficient. As difficult as the task may be, it will be an incremental change in individual buildings over time that makes the difference [37]. Thus, each stakeholder involved in building design and construction has a role to play in finding solutions to the crisis our planet faced with [17].

Understandably, low-income household energy cost is four (4) times more than for other American households. Even though energy bills comprise a significant percentage share of a typical low-income family's budget, it is clear that utility costs seen as an overlooked component of housing costs. The key task is to comprehend clearly that affordable housing can be made to be energy efficient without afflicting cost overruns and delays at the construction stage of the projects. It is also evident that the benefits to be realized will have a significant effect on housing affordability and the tenant's willingness to pay for housing bills and rental costs as well as living in a comfortable home. This paper seeks to demonstrate the benefits of BEE affordable housing and how minimizing building energy efficiency TCs can overcome the developer-owners' misconception that achieving BEE affordable housing is typically expensive and time intense. It is argued that BEE lowers utility bills, which eventually enhances home affordability.

\subsection{Barriers to building energy efficiency affordable housing}

The leading barriers to energy efficiency as identified are energy prices and technology; limited capital access; lack of or inadequate information; incorrect risk assessment; the principal/agent problem; and transaction costs in energy efficiency. As posited by Valentova [18], the barriers are all usually interconnected, and they may even reinforce each other as against being in a standalone form.

Energy prices affect the application of energy efficiency measures in several ways. The real stake of energy costs in total costs and the development of energy prices seen as key factors in energy price. On the other hand, a barrier that often cited with regards to energy efficiency measures is the extraordinary upfront costs of energy efficiency investments which affect limited access to capital. The small and medium-sized enterprises (SME) and as well as the lower income group "households" are generally perceived to be predisposed by these barriers. Furthermore, due to the lack of or inadequate information to prospective investors, in both organizations and households, the energy saving costs measures are expected to go beyond the individual user's benefits [19], which is seen to be more related to TCs.
Incorrect risk assessment: In general, employing an extremely high discount rate in evaluating the economic efficacy of energy saving measures is a hypothesis as a key source of the alleged "efficiency gap" [20, 21]. Numerous empirical findings have indicated that customers that is "firms and households" cut the price of energy savings by $10 \%$, therefore considerably reducing their present value $[20,22,23]$. Howarth \& Anderson [19] found that the estimate of the price cut rates begins from $20-25 \%$ but can stretch up to $80 \%$, which is far higher than the returns on other investments could provide. Similarly, Vine et al. [24], establish that the level of the price cut rate or discount rate can stretch up to $50 \%$. Hence, there are several motives for this, but they all reflect the barriers discussed earlier.

The principal-agent problem: The "principle-agent" issue is essentially a split incentives barrier "or the separation of responsibilities for energy expenditures and conservation actions" [25]. The owners of the rental unit have the incentives and motivation to invest in building energy efficiency measure. Additionally, the home/building owner will not receive direct benefits of the efficiency measure applied; this is because the enduser or tenant is seen to be paying lesser bills for energy consumption. On the contrary, the end-user or tenant obtains all the relevant benefits from the homeowner investment on energy efficiency measure, but then with no or lack of incentive to invest, as there is high uncertainty with regards to the contract delivery timeframe. The end-user or tenant may likely move out to another place before reaping or realizing the full benefits of energy saving costs, which is detrimental to the investment from an economic viewpoint. Schleich \& Gruber, [26] posit that split incentives barrier is seen as highly important for households or tenants than private firms and as well as the public sector. This is also seen to have a more extended rental contract than in the households' situation.

\section{Transaction costs in building energy efficiency}

Transaction costs are portrayed distinctly because they are likely to comprise all the barriers mentioned above. The level of TCs is not insignificant, and it is expected to inhibit building energy efficiency measures from clearly being executed. Though, the actual amount or quantity of TCs remains vague and uncertain, partly due to the nonexistence of a precise method for evaluation that can be considered in decision-making processes. Previous studies have found that the TCs in building energy efficiency is factual and is projected to be on a significant level. TCs might hinder the practice of energy efficiency measures in a project, or may eventually offset the benefits achieved or sustained in energy efficiency improvements scenarios and hence lead to their minimal benefits realization.

Matthews [27] provides a seemly consistent definition of TCs in energy efficiency "as the costs of arranging a contract ex-ante and monitoring and enforcing it ex-post, as opposed to production costs." It 
can be applied to both efficiency measures investment and policy instruments. TCs are borne either by the developers, project managers or by the BEE project beneficiaries. The transaction costs, therefore, pertain to the costs related to investment, operation, and maintenance, verification, or administrative costs. Lack or inadequate information and TCs are often interchangeably used in the literature [26]. It is evident that energy efficiency TCs can be alienated into four (4) main groups or stages in which TCs can occur; at the planning stage, implementation stage, monitoring stage and the verification stage (refer to Table 1).

Table 1. Sources of TCs [28, 18].

\begin{tabular}{|c|c|}
\hline Project value & Nature of transaction costs \\
\hline Planning & $\begin{array}{l}\text { - TCs related to information search } \\
\text { - TCs related to customers' search } \\
\text { - TCs related to legal fees } \\
\text { - Proposal development stage } \\
\text { - Identification and evaluation }\end{array}$ \\
\hline Implementation & $\begin{array}{l}\text { - Contracts negotiation } \\
\text { - Project procurement stage } \\
\text { - Validation stage }\end{array}$ \\
\hline $\begin{array}{l}\text { Monitoring \& } \\
\text { Verification }\end{array}$ & $\begin{array}{l}\text { - Monitoring, quantification, and } \\
\text { verification of savings mechanism } \\
\text { and related greenhouse gas } \\
\text { emissions reductions }\end{array}$ \\
\hline
\end{tabular}

At the planning stage involves information searching, project identification, proposal development, and evaluation. While at the project value implementation stage, the negotiation process is essential. The last stage essentially means to monitor and verify energy savings and as well as greenhouse gas emissions reductions.

Bjorkqvist and Wene [29] also highlight the importance of taking into consideration potential active rejection within the calculation. Active rejection described as an option that actors take into consideration before active rejection. The actors also incur TCs. Generally, the understanding of the adverse effect of TCs has been supported by several studies as identified in the literature (such as in $[30,31,32,22,12])$. Though, there is a lack of inadequate empirical data in the literature. This is due to the fact actors are often seen to be unwilling to reveal information. Additionally, there is a lack of post-evaluations or assessment, which serve as an essential source for TCs estimation. Besides, it is evident that TCs are understandably specific concerning a case [33].

The findings from previous studies that evaluate the level of TCs in different programs are discussed below. It is significant to note that, due to the diversity of sectors and methods applied, the findings could not directly be analysed in a comparative form.

Bjorkqvist \& Wene [29] carried out a study of TCs in households that were involved in Goteborg demand side management program. Fifty-one households that invested in their home heating systems upgrade were analyzed. The TCs have not assessed the intangible value or monetary terms, but rather in hours spent by the households. It was found that the household spent 18 hours on average in the decision-making process. Six hours was found to be the time spent by (active rejection) or non-investors. Interestingly, the energy supplier who seen as the principal initiator of the demand side management program was found to have provided significant information such as the potential dealer or suppliers of energy efficiency equipment, and options information. In this regards, the "time" for searching information indeed saved.

Bjorkqvist \& Wene further transform the hours into tangible value or monetary terms, by using labor costs as a proxy. The TCs then was found to represent $28 \%$ of the average investment that is when considering gross income, or $13 \%$ if net income considered. They acknowledged that the values may have underestimated because it is difficult for the households explicitly recall all time spent on the decision and, because the distribution company engaged at the decision making process, they provide significant relevant information that is required.

Similarly, Michaelowa \& Jotzo [34] carried out a study to evaluate the TCs of numerous greenhouse gas emissions schemes, specifically the AIJ in Sweden. The key sources of TCs in these schemes were the search information costs, baseline development, approval costs, validation as well as registration and monitoring. A substantial fixed part in the TCs in the greenhouse gas schemes found. This reflects a certain threshold of $\mathrm{CO}_{2}$ savings below which the TCs eventually offset the benefits realized in the project. In addition, a similar study established the threshold at $50000 \mathrm{t} \mathrm{CO}_{2}$ per year for a 20 -year project. Michaelowa \& Jotzo posits that TCs value should exceed $25 \%$ of the proceeds from permit sales in order to make a project more feasible [34]. By and large, the level of TCs was estimated at $20.5 \%$ of the overall total project value. Refer to Table 2 below for the experiential estimates of TCs

Table 2. Experiential estimates of TCs [18]

\begin{tabular}{|c|c|c|c|}
\hline Author & $\begin{array}{l}\text { TCs } \\
\text { Level } \\
\end{array}$ & Sector & Remarks \\
\hline $\begin{array}{l}\text { Bjorkqvist et } \\
\text { al. [29] }\end{array}$ & $\begin{array}{l}28 \% \\
(13 \%)\end{array}$ & Household & $\begin{array}{l}\text { That is when gross } \\
\text { (net) income } \\
\text { referred to }\end{array}$ \\
\hline $\begin{array}{l}\text { Michaelowa } \\
\& \text { Jotzo [34] }\end{array}$ & $20.5 \%$ & $\mathrm{CDM}$ & $\begin{array}{l}\text { Clean } \\
\text { Development } \\
\text { Mechanism }\end{array}$ \\
\hline Mundaca [33] & $10-20 \%$ & $\begin{array}{l}\text { Audit } \\
\text { scheme }\end{array}$ & $\begin{array}{l}\text { Percentage of the } \\
\text { audit costs }\end{array}$ \\
\hline Mundaca [33] & $8-12 \%$ & Lighting & $\begin{array}{l}\text { Energy savings } \\
\text { target program }\end{array}$ \\
\hline Mundaca [33] & $24-36 \%$ & Insulation & $\begin{array}{l}\text { Energy savings } \\
\text { target program }\end{array}$ \\
\hline Sathaye [35] & $9-19 \%$ & $\begin{array}{l}\text { Not } \\
\text { specified }\end{array}$ & \\
\hline $\begin{array}{l}\text { Easton } \\
\text { Consultants }\end{array}$ & $20-40 \%$ & ESCOs & $\begin{array}{l}\text { Energy Services } \\
\text { Companies }\end{array}$ \\
\hline
\end{tabular}




\begin{tabular}{|l|l|l|l|}
\hline$[36]$ & & & \\
\hline
\end{tabular} In another development, Mundaca [33] analyzed "free of
charge energy audits" in Denmark, as well as the "energy efficiency commitment" in Great Britain. The findings on the "free of charge energy audits" could not be regarded as statistically relevant, this based on the fact that only five (5) replies were received and considered. On the other hand, a qualitative data analysis employed. The fact is that the energy providers have to carry out an energy audit of their customers. The justification for the program is perceived asymmetric information by the market agents, though, the chances of leveraging on all the energy improvements are minimal. The TCs are mainly related to the searching for potential clients for the audit, conduct the audit, and eventually follow up on the measures, with regards to partners' search, when the client resolves to execute some building energy efficiency measures. In addition, another key source of TCs is the accreditation process, in which an energy audit is expected to convey as part of the program. It was found that 10 to $20 \%$ of the direct costs of the energy audit to be the estimated TCs and not the prospective investment costs.

On the other hand, Mundaca [33] attempt to identify and measure or quantify the TCs that have a relationship with energy efficiency program. The established TCs were fundamentally information searches on the household that intent to save, customers persuasion or approval of building energy efficiency measures by the relevant authority. In the same vain, contracts negotiations or agreements with a third party in verification and monitoring were found to be key fundamental sources of TCs at the implementation stage. All put together; the TCs level varied following the building energy efficiency measures employed. The TCs in lighting ranged from $8 \%$ to $12 \%$, and BEE insulation measures the range from 24 to $36 \%$ of the total investment value.

Finally, Sathaye [35] found an estimated TCs which range between $9 \%$ to $19 \%$ of the total project value concerning greenhouse gas emission reduction projects in Asia, North and South America. The TCs were established to be borne essentially from the contract negotiation process amongst parties, feasibility studies, monitoring, and evaluation as well as from relevant authorities' approval. In addition, Sathaye further believes that a key aspect defining the level of TCs specifically in greenhouse gas projects is the project size. A few research has also shown commitment and concentrated on the TCs borne by Energy Service Companies (ESCOs). An estimated TCs of $20 \%$ to $40 \%$ of the total project value was established by Easton Consultants [36] in energy efficiency projects executed by ESCOs (refer to Figure 2) below.

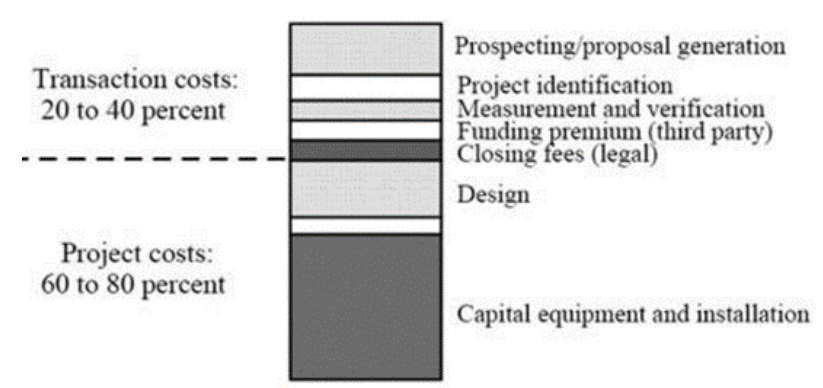

Fig. 2. TCs related to ESCO project [36]

\section{Conclusion}

Inadequate or lack of competency which results in bounded rationality; and transaction characteristics such as split incentive, information asymmetry, developer opportunistic behaviour, ill-informed users and institutional transition can trigger additional TCs in BEE affordable housing delivery. Viewing the problem from an analytical sociotechnical perspective and focusing on developer capability with respect to human action to minimize TCs, two latent constructs identified from literature as components of developer organizational capability namely: developer team-competency and team-commitment. Hence, it proposed that, in order to minimize building energy efficiency TCs, developer team-competency and team-commitment needs to be given greater prominence in order for affordable housing projects to leverage on its full benefits with respect to making homes much more affordable to live in, with lower utility bills and high building performance.

This research fully supported by the Tertiary Education Trust Fund (TETFUND) Nigeria. The author fully acknowledged Bayero University, Kano for the support which has made this important research possible.

\section{References}

1. M. Levine, D. Urge-Vorsatz, K. Blok, L. Geng, D. Harvey, Residential and commercial buildings. In Climate Change 2007 Mitigation Contribution of Working Group III to the Fourth Assessment Report of the Intergovernmental Panel on Climate Change, 389-437 (2007)

2. WBCSD, Energy Efficiency in Building: Business realities and opportunities. World Business Council for Sustainable Development (2009)

3. O. Ugwu, T. Haupt, Key performance indicators and assessment methods for infrastructure sustainability - a South African construction industry perspective. Building and Environment, 42(2), 66580 (2007)

4. Q. Qian Kun. Barriers to Building Energy Efficiency (BEE) promotion: A transaction costs perspective.

5. Nigeria National Building Energy Efficiency Code. (2017) 
6. G. Ofori, S.R. Toor. Leadership: A pivotal factor for sustainable development. Construct. Inform. 10. 6772 (2008)

7. M. Delnavaz. Project Managers' Role in Sustainable Building Process. Master's Thesis, Department of Civil and Environmental Engineering, Chalmers University of Technology, Göteborg, Sweden. 50. (2012)

8. S.R. Toor. G. Ofori. Leadership for future construction industry: Agenda for authentic leadership. Int. J. Proj. Manag. 26. 620-630 (2008)

9. G. Akerlof. The market for lemons: quality uncertainty and the market mechanism. Journal of Economics. 84. 488-500 (1970)

10. L. Koskela. An exploration towards a production theory and its application to construction. VTT Technical Research Centre of Finland. (2000)

11. Y. Wenan. W. Mengjun. A study on constructing index systems of construction market performance appraisal. InIntelligent Computation Technology and Automation (ICICTA), 2010 International Conference, 1. 361-364. IEEE (2010)

12. C.P. Gomez. A.U. Raji, Investigating organizational capability vis-à-vis human action to minimize postcontract transaction costs in D\&B projects. 27-34 (2017).

13. R.E. Boyatzis. Competencies in the 21st century. Journal of management development. 27(1).5-12. (2008)

14. O.E. Williamson. The economics of organization: The transaction cost approach. American Journal of Sociology.87(3).548-77.(1981)

15. Q.K. Qian. S. Lehmann. A.G. Khalid. E.H. Chan. Transaction costs (Tcs) framework to understand the concerns of building energy efficiency (BEE) investment in Hong Kong. International Journal of Waste Resources. .4(1):135-41.(2014)

16. Q.K. Qian, E.H. Chan, A.G. Khalid. Challenges in delivering green building projects: Unearthing the transaction costs (TCS). Sustainability. 7(4):361536.(2015)

17. J. McIlwain. S. Kermit, It's Easy Being Green. Multifamily Trends, pp.20-21.(2006)

18. M. Valentová. Barriers to Energy Efficiency-focus on transaction costs. Acta Polytechnica. ;50(4).(2010)

19. R.B. Howarth, B. Anderson. Market barriers to energy efficiency. Energy Economics, p. 262272.(1993)

20. P.B. Thompson. Evaluating energy efficiency investments: accounting for risk in the discounting process. Energy Policy, Vol. 25, No. 12, p. 989996.(1997)

21. C.C. Koopmanss, D. Willem Te Veld. Bridging the energy efficiency gap: using bottom-up information in a top-down energy demand model. Energy Economics, Vol. 23, No. 1, p. 57-75(2001)
22. A.H. Sanstad, R.B. Howarth. "Normal" markets, market imperfections and energy efficiency. Energy Policy, Vol. 22, No. 10, p. 811-818.(1994)

23. V, Oikonomou, M. Rietbergenb,M. Patelbet. An exante evaluation of a White Certificates scheme in The Netherlands: A case study for the household sector. Energy Policy, Vol. 35, p. 1 147-1 163 (2007)

24. E. Vine, G. Kats, J. Sathaye, H. Joshi. International greenhouse gas trading programs: a discussion of measurement and accounting issues. Energy Policy, Vol. 31, No. 3, p. 211-224 (2003)

25. E. Jochem, E. Gruber. Obstacles to rational electricity use and measures to alleviate them. Energy Policy, Vol. 18, no. 4, p. 340-350 (1990)

26. J. Schleich, E. Gruber. Beyond case studies: Barriers to energy efficiency in commerce and the services sector. Energy Economics, Vol. 30, p. 449-464 (2008)

27. R. Matthews. The economics of institutions and the sources of growth. The Economic Journal, Vol. 96, No. 384, p. 903-918 (1986)

28. L. Mundaca, L.Neij. Transaction costs of energy efficiency projects: A review of quantitative estimations. Report prepared under Work Package 3 of the Euro White Cert project, (2006)

29. O. Bjorkqvist, C. Wene. A study of transaction costs for energy investments in the residential sector. In Proceedings of the 1993 Summer Study. The European Council for an Energy Efficient Economy (ECEEE), Stockholm, p. 23-30.(1993)

30. K. Ostertag. Transaction costs of raising energy efficiency. International workshop on technologies to reduce greenhouse gas emissions: Engineeringeconomic analyses of conserved energy carbon Washington D.C., USA, (1999)

31. K. Ostertag. No-regret Potentials In Energy Conservation: An Analysis Of Their Relevance, Size And Determinants, Springer Berlin : Heidelberg, (2003).

32. A. Reddy. Barriers to improvements in energy efficiency. Energy Policy, p. 953-996.(1991)

33. L. Mundaca. Transaction costs of energy efficiency policy instruments. In Proceedings of the ECEEE 2007 Summer Study - Saving Energy - Just Do It!, edited by Attali, S. and Tillerson, K., ECEEE: Stockholm, p. 281-291(2007)

34. A. Michaelowa, F. Jotzo. Transaction costs, institutional rigidities and the size of the clean development mechanism. Energy Policy, Vol. 33, p. 511-523 (2005)

35. J.A. Sathaye. Expediting energy efficiency project methodologies. Bonn, Germany, Lawrence Berkeley National Laboratory, (2005).

36. Easton Consultants, S. F. M. C.: Energy Service Companies. A Market Research Study, Prepared for Energy Center of Winsconsin: 64, (1999) 
37. Nigerian National Building Energy Efficiency Code. Available from http://www.pwh.gov.ng. 